\title{
ANÁLISIS DE LAS ACTUACIONES DE PROTECCIÓN AMBIENTAL Y GESTIÓN TURÍSTICA EN EL PARQUE REGIONAL DE CALBLANQUE, MONTE DE LAS CENIZAS Y PEÑA DEL ÁGUILA (MURCIA, SE ESPAÑA)
}

\author{
Francisco Belmonte Serrato \\ Gustavo A. Ballesteros Pelegrín \\ Miguel Ángel Sánchez Sánchez \\ Universidad de Murcia
}

\section{RESUMEN}

El Parque Regional de Calblanque, Monte de las Cenizas y Peña del Águila tiene 2.822 ha y más de $13 \mathrm{Km}$ de costa en los municipios de Cartagena y la Unión. Con el objetivo de evaluar la gestión, conservación ambiental y turística entre 2000-2017, se utiliza como metodología el análisis de las memorias e informes de la administración. El resultado es la participación de 7 profesionales, un presupuesto anual superior a 600 mil euros para mantenimiento y limpieza, vigilancia, información y atención al visitante, infraestructuras y equipamientos de uso público, conservación de unas salinas, del bosque de Tetraclinis articulata y limitación de accesos de vehículos en verano.

Palabras clave: conservación, control, gestión, Parque Regional, turismo.

Fecha de recepción: 10 de enero de 2018

Fecha de aceptación: 2 de mayo de 2018

Departamento de Geografía. Universidad de Murcia. Campus de La Merced. 30001 MURCIA (España). E-mail: franbel@um.es,gabp1@um.es, miguelangel.sanchez2@um.es 


\title{
Analysis of the activities of environmental protection and tourist management in the Regional Park of Calblanque, Monte de las Cenizas and Peña del Águila (Murcia, SE Spain)
}

\begin{abstract}
The Regional Park of Calblanque, Monte de las Cenizas and Peña del Águila has 2,822 hectares and more than $13 \mathrm{~km}$ of coastline in the municipalities of Cartagena and La Union. With the objective of evaluating the management, environmental and tourist conservation between 2000-2017, the analysis of the reports and reports of the administration is used as a methodology. The result is the participation of 7 professionals, an annual budget of over 600 thousand euros for maintenance and cleaning, surveillance, information and visitor assistance, infrastructures and equipment for public use, conservation of some salt mines, the Tetraclinis articulata forest and limitation of vehicle accesses in summer.
\end{abstract}

Key words: conservation, control, management, Regional Park, tourism.

\section{INTRODUCCIÓN}

Los espacios naturales costeros se presentan cada vez con mayor fuerza como un recurso turístico potencial que precisa y demanda de una gestión orientada a la protección y sostenibilidad a largo plazo. Las playas y calas accesibles y con potencial uso turísticorecreativo, están adquiriendo una importante relevancia social y económica, por lo que es necesario analizar, evaluar y regular ciertas actividades compatibles con sus recursos naturales. En este sentido las comunidades autónomas y los estados deben utilizar y conservar dichos recursos para ofertar actividades seguras y garantizar la conservación de los valores naturales por los que estos territorios fueron protegidos. De esta manera, va tomando fuerza la necesidad de incorporar en los planes de gestión de espacios naturales costeros sistemas de gestión integral partiendo de diagnósticos que suelen presentar un nivel de gestión débil, falta de ordenación del funcionamiento de la playa, carencia de una visión preventiva, insuficiencia en la recogida de indicadores e información, etc.

Durante las últimas décadas del siglo XX y las primeras del siglo XXI se ha ido reforzando la percepción social de la conservación, haciendo visibles los estrechos vínculos que existen entre la naturaleza y el bienestar humano. La idea-fuerza de que los ecosistemas y en especial la biodiversidad que albergan, constituyen un capital natural que es necesario conservar, al menos en unos niveles críticos, ya que generan toda una serie de servicios, como alimentos, madera, agua, pesca, control del sistema climático, depuración del agua, formación de suelo, regulación de enfermedades, asimilación de nutrientes, etc., sin olvidar sus valores estéticos, educativos, de ocio o espirituales. Estos servicios de los ecosistemas tienen consecuencias en la prosperidad de la sociedad humana y no sólo en su economía, sino también en la salud, en las relaciones sociales, en las libertades o en la seguridad. Además hay que tener en cuenta que muchos de estos servicios son invisibles 
al mercado, por lo que no tienen precio y por consiguiente no están suficientemente valorados por la sociedad de cara a su conservación (Martín López y Montes, 2009).

Hay que considerar que el turismo masivo, sin una gestión adecuada, puede verse como un riesgo en aquellas zonas donde múltiples actividades se desarrollen sin ningún tipo de control, provocando impactos ambientales negativos y llegando a alterar el paisaje o la calidad del agua del lugar. Por las razones expuestas, se deben fijar nuevos retos y adoptar nuevas formas de gestión del litoral que aseguren unos estándares de calidad y de gestión medioambiental para salvaguardar a largo plazo los recursos naturales y provocar el mínimo impacto que se deriva en buena medida del desarrollo de la actividad turística (Macías-Otón, 2011).

Actualmente los sistemas integrales de gestión ambiental son cada vez más relevantes y proporcionan unas bases para lograr un equilibrio entre los actores implicados y encaminar los objetivos hacia una mejora continua y hacia la sostenibilidad, poniendo de manifiesto la necesidad de un cambio y una reflexión sobre el uso turístico de los espacios naturales costeros. Dichos sistemas pretenden involucrar a los diferentes actores, organismos públicos y privados así como al usuario final, en el caso de espacios litorales costeros estos sistemas generan mecanismos de control de accesos para regular el número de vehículos a motor en el interior de espacios protegidos.

El Parque Regional de Calblanque, Monte de las Cenizas y Peña del Águila, es un Espacio Natural Protegido de la Región de Murcia de gran valor, tanto ecológico, como turístico y recreativo, geológico y cultural. La gente que llega al parque puede disfrutar de una gran oferta recreativa, con rutas de senderismo guiadas por el personal del parque o paseos en bicicleta, en los que se puede apreciar la gran riqueza tanto botánica con especies vegetales únicas, como de fauna silvestre asociada a zonas húmedas y áreas desérticas. También se pueden observar algunos estratos geológicos como las dunas fósiles o visitar la batería militar abandonada de Las Cenizas, declarada Bien de Interés Cultural por la ley de Patrimonio Histórico Español. Todo ello sin olvidar las impresionantes vistas que se pueden observar desde la cima del Monte de la Cenizas, o las actividades deportivas en sus aguas como el windsurf o el skysurf, o disfrutar de un buen baño en época estival.

El gran atractivo del Parque ha favorecido un progresivo incremento del número de visitantes a lo largo de estas últimas décadas. La ausencia en la limitación del número de vehículos que acceden al parque ha favorecido situaciones de colapso en la capacidad de acogida de aparcamientos y playas durante el periodo estival que se han ido incrementado a lo largo de los años, con efectos negativos como polvo excesivo en el entorno de los caminos de acceso y del interior del Parque con problemas de degradación de la vegetación, accidentes de tráfico, etc. y problemas en los aparcamientos, con ausencia de plazas libres, estrés de los conductores, vegetación dañada debido a los estacionamientos indebidos en los exteriores de los aparcamientos, etc. (Jordán, 2009).

Hasta el inicio de las actuaciones de control de accesos en 2010, el masivo flujo de vehículos motorizados en el interior del parque durante el periodo estival superaba la capacidad de acogida admisible, especialmente en las zonas de playa, suponiendo un factor de degradación de sus valores naturales y paisajísticos, cuya conservación constituye una de las finalidades de su declaración como espacio natural protegido (Figura 1). 


\section{Figura 1 \\ PLAYA DEL PARQUE REGIONAL DE CALBLANQUE, MONTE DE LAS CENIZAS Y PEÑA DEL ÁGUILA}

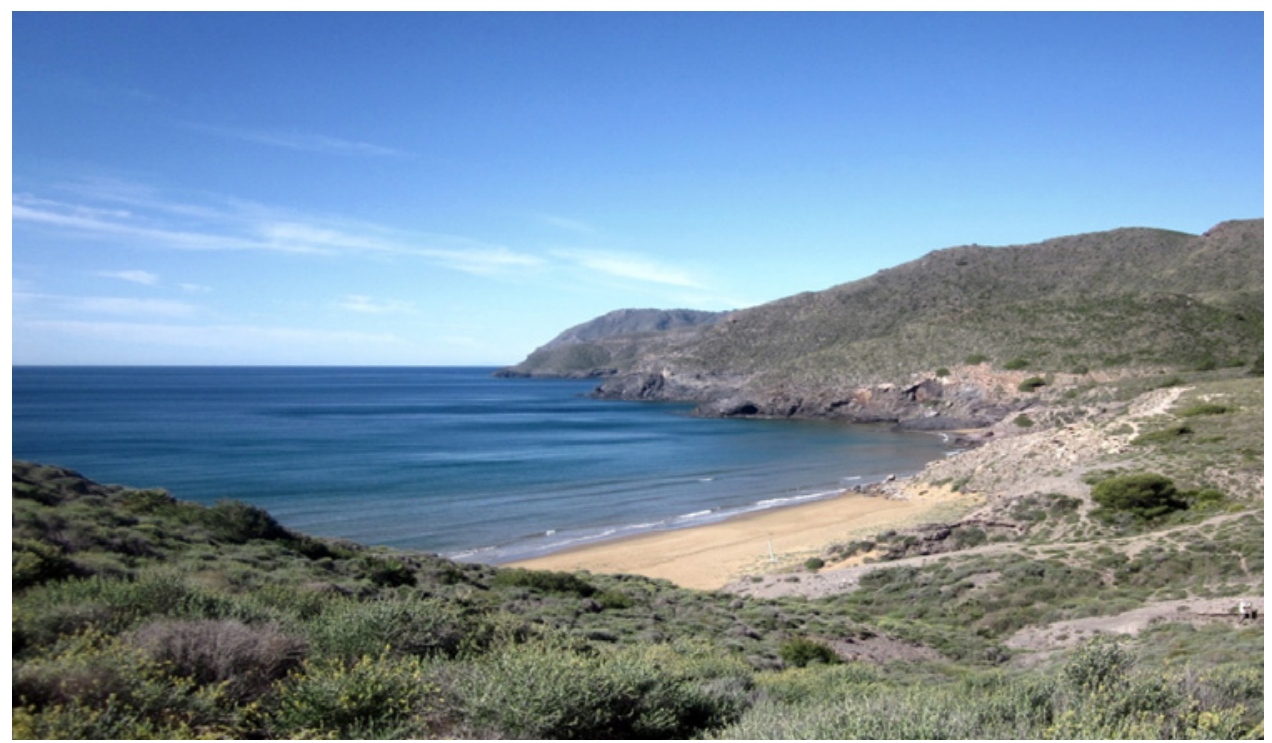

Fuente: Autores.

La regulación del acceso a las playas del Parque Regional de Calblanque, se basa en el establecimiento de un valor de capacidad de acogida, de modo que una vez superada, se ponga en marcha un dispositivo alternativo que permita la entrada de los visitantes a las playas sin sobrepasar la capacidad de acogida de los aparcamientos y de la red viaria que da servicio a las playas. El concepto de capacidad de acogida que fue aplicado a la gestión de visitantes del Parque Regional, en términos generales, trata sobre el nivel máximo de visitantes que puede soportar dicho espacio, sufriendo el menor impacto ecológico y a la vez aportando el mayor grado de satisfacción a los usuarios (Jordán, 2009).

Pero este concepto no es fácil de determinar, ya que tiene que tener en cuenta varias cuestiones tales como: tipología del visitante, condiciones de su visita (duración, actividades que piensa desarrollar...), espacio físico disponible, generación de impactos ambientales sobre el medio, capacidad de gestión del área y disponibilidad de equipamientos (González-Reina, 2012).

Por tanto, el concepto de capacidad de acogida suele estudiarse en función de los siguientes componentes (Boo, 1995): Capacidad de acogida física, es la relacionada con sus características espaciales (dimensiones, accesibilidad,...); capacidad de acogida ecológica, relacionada con los impactos que pueden corregirse o ser absorbidos, rechazando un número de visitantes que provocan impactos por encima del límite de cambio aceptable; capacidad de acogida psicológica, es la que se asocia a una experiencia satisfactoria del visitante y viene determinada en muchos casos por la percepción sobre el nivel de masi- 
ficación del destino elegido por el usuario; capacidad de acogida recreativa, relacionada con el número máximo de usuarios que admite un lugar o equipamiento, por encima de este se verían deterioradas tanto la calidad ambiental como la recreativa.

Al revisar otras experiencias en materia de ordenación de accesos a nivel nacional e internacional, se aprecia que es algo casi generalizado y normal en los diferentes parajes naturales (Álvarez, 2016; Gómez-Limón y García-Ventura, 2014).

En España hay espacios, que al igual que en el Parque Regional de Calblanque, Peña del Águila y Monte de las Cenizas, han puesto en marcha actuaciones de ordenación de accesos en los períodos de máxima afluencia de visitantes (Gómez-Limón y GarcíaVentura, 2014; López, 2009, Flores \& Barrosos, 2012), facilitando en algunos casos, la entrada en autobús mediante una aportación económica para el mantenimiento del servicio, como es el caso del Parque Natural de Cabo de Gata Níjar, Parque Nacional de Monfragüe y Parque Nacional del Teide (Muñoz-Flores, 2016; Martín-Perera, 2016;

En algunos espacios naturales existe horario de apertura y cierre, en otros es necesario comprar un permiso para realizar la visita y/o se permite la entrada con vehículo a motor y en otros casos está prohibido, obligando a coger el autobús, incluso en algunos países existe la posibilidad de comprar un pase anual que permite la entrada a todos sus espacios protegidos (González-Reina, 2012; National Parks Service U.S., 2017).

Existen diversos trabajos sobre análisis temporales relacionados con el acceso a espacios naturales y conservación, por ejemplo: Dóniz-Páez et al. (2010), Strickland-Munro \& Moore (2014) y Ballesteros-Pelegrín (2014), pero no se dispone de estudios que analicen el control de accesos a espacios naturales con el análisis global de las acciones de conservación y gestión que anualmente se desarrollan. Por tanto, el objetivo de este trabajo es analizar las iniciativas de gestión desarrolladas en el Parque Regional en el periodo 2010-2017, prestando especial atención al control de accesos que se desarrollan durante el periodo estival.

\section{2. ÁREA DE ESTUDIO Y METODOLOGÍA}

El Parque Regional de Calblanque, Monte de las Cenizas y Peña del Águila, se encuentra al sur de la cuenca del Mar Menor, en la parte más oriental del litoral de la Región de Murcia, siendo uno de los ocho espacios protegidos con la categoría de Parque Regional con que cuenta esta comunidad autónoma.

Con una superficie de 2.822,45 ha, se extiende por más de $13 \mathrm{~km}$ de costa e incluye territorios correspondientes a los términos municipales de Cartagena y La Unión (Figura 2) (Cavero-Sáncho, 1999). Este espacio es una de las pocas zonas de la costa murciana que todavía permanece prácticamente inalterada, con presencia de Posidonia oceánica en la zona infralitoral (OISMA, 2016 ${ }^{\mathrm{a}}$ ).

Entre los aspectos más importantes se debe mencionar su gran variedad de tipos de vegetación, consecuencia del encuentro de múltiples ambientes naturales, entre las que cabe destacar los sabinares, por su rareza y singularidad, destacando por su mayor envergadura los pies de sabina mora (Tetraclinis articulata), siendo las sierras del parque donde se encuentra la mejor población europea de esta sabina. Otros endemismos característicos son la jara de Cartagena (Cistus heterophyllus subsp. carthaginensis), cuya población es 
muy reducida y su área de distribución está muy localizada, y la siempreviva de Cartagena (Limonium carthaginense) (Alcaraz, et al., 2008). Entre las especies animales protegidas está el fartet (Aphanius iberus), el águila perdicera (Aquila fasciata), el búho real (Bubo bubo) y la terrera marismeña (Calandrella rufescens) (OISMA, 2016a).

El espacio dispone de una serie de instrumentos de gestión vinculados a la declaración de Parque Regional por la Ley 4/1992 de Ordenación y Protección del Territorio de la Región de Murcia. Su Plan de Ordenación de Recursos Naturales se aprobó por Decreto en 1995 (Dirección General de Medio Natural, 1995). Es, además, Lugar de Importancia Comunitaria (LIC), quedando amparado por la Unión Europea en el marco de la Directiva 92/43/CEE del Consejo, de 21 de mayo de 1992, relativa a la conservación de los hábitats naturales y de la fauna y flora silvestres (Unión Europea, 1992).

Dentro del propio Parque Regional, las Salinas del Rasall, que ocupan una superficie de 18 hectáreas, forman parte de la Zona de Especial Protección para las Aves (ZEPA) Mar Menor (Unión Europea, 2009), contando con una interesante avifauna acuática. Además de ser incluidas, también junto al Mar Menor, con el número 706, en la Lista de Humedales de Importancia Internacional del Convenio de Ramsar (Consejo de Ministros, 1994).

\section{Figura 2}

\section{LOCALIZACIÓN DEL PARQUE REGIONAL DE CALBLANQUE, MONTE DE LAS CENIZAS Y PEÑA DEL ÁGUILA}

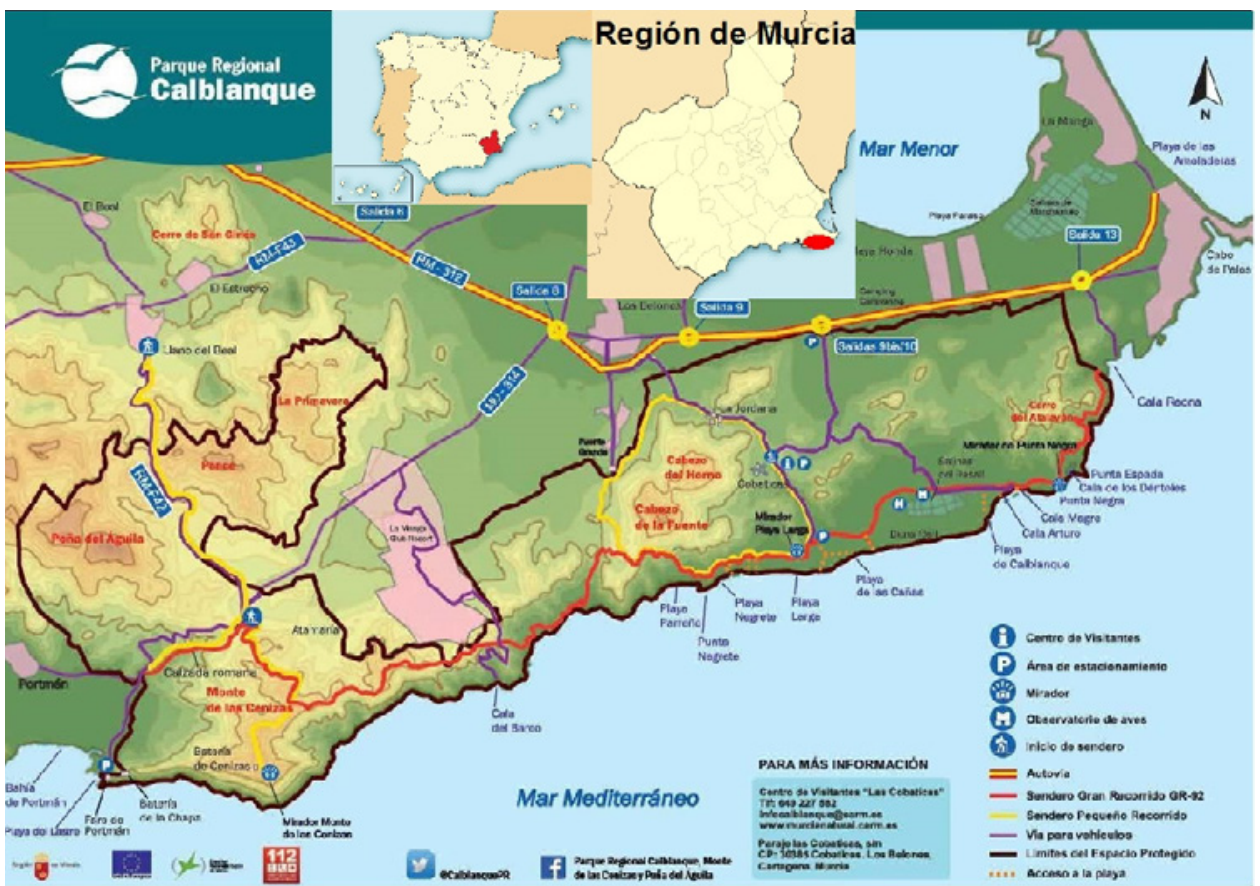

Fuente: murcianatural (2018). 
Para la realización de este trabajo se han consultado todos los documentos disponibles mediante internet en la página http://www.murcianatural.carm.es/web/guest y aquellos otros suministrados por la Dirección General de Medio Ambiente de la Región de Murcia, que forman parte de la documentación suministrada a los miembros de la Junta Rectora del Parque Regional, y cuyo uso fue autorizado mediante resolución de la Dirección General de Medio Natural con fecha de registro $n^{\circ} 20180005930$ y fecha de salida de 15 de enero de 2018.

Las diferentes iniciativas que se desarrollan en el Parque Regional genera anualmente la elaboración de 3 tipos de memorias diferentes: Memoria Anual de Gestión, Memoria Anual del Programa de Información y Atención al Visitante y la Memoria Anual del Control de Accesos, además de las actas de los debates que se generan en el seno de la Junta Rectora del Parque. Por tanto, se dispone de una excelente información sobre los esfuerzos por mantener este espacio en el mejor estado de conservación posible.

Para la elaboración de este trabajo se han consultado las memorias anuales de gestión de 2010 a 2015, las memorias anuales del servicio de información de 2010 a 2016, las memorias e informes sobre regulación de accesos de 2010 a 2017, así como otros documentos y actas suministrados a las Juntas Rectoras del Parque de 2012 a 2017 y que han sido cedidos por la Administración regional para ser utilizados en este trabajo (Dirección General de Medio Ambiente 2010, 2011, 2012a, 2012b, 2013 a 2013b, 2014 a , 2014b; OISMA 2015a, 2015b, 2016a, 2016b y 2017).

La metodología empleada para evaluar los recursos para la gestión, el mantenimiento y servicios turísticos en lo que se refiere al personal de la administración regional y personal adscrito a servicios básicos externos, ha sido mediante el cálculo del número de horas anuales que cada persona destina al Parque de las tareas que le son encomendadas. El funcionamiento de los servicios básicos se ha calculado mediante el presupuesto anual de inversión. Las actuaciones de mantenimiento y limpieza, mediante el cálculo del número de horas de trabajo en cada una de las tareas de mantenimiento de las infraestructuras y actividades de apoyo a la gestión y conservación, así como el número de kg de residuos sólidos urbanos recogidos. Con respecto a las actuaciones de prevención de incendios forestales, se han calculado el número de hectáreas desbrozadas y/o aclaradas destinadas a fajas auxiliares y/o áreas cortafuegos. Respecto a la información, atención al visitante y comunicación social, se ha contabilizado el número de personas informadas y su procedencia en el centro de visitantes del Parque. Con respecto a las iniciativas de otras administraciones y organizaciones sociales, se ha contabilizado el número de autorizaciones concedidas. Las actuaciones específicas en conservación del patrimonio natural y cultural, mantenimiento de infraestructuras y equipamientos de uso público, así como acciones de investigación, estudio y participación social, han sido evaluadas atendiendo a volumen de inversiones realizadas.

Finalmente, la metodología empleada para evaluar la ordenación de acceso turístico durante el periodo estival, ha sido cuantificar la capacidad de acogida de los 7 aparcamientos de las playas, en base a la disponibilidad para cada vehículo de la superficie suficiente para realizar el aparcamiento y maniobrabilidad en su interior, el respeto a las especies vegetales existentes en el perímetro de los aparcamientos, evitando que los vehículos afecten negativamente a las mismas; garantizar el tránsito y maniobrabilidad 
de los autobuses lanzadera que presten servicio a los visitantes que no puedan acceder en vehículo al Parque, reservar espacio suficiente para instalar sus infraestructuras asociadas (marquesinas de protección solar); respeto a los accesos a las playas, a través de senderos que transcurren por los aparcamientos; así como mantenimiento de la superficie requerida para emplazar contenedores de basuras, señalización informativa, etc. y tratamiento del efecto psicológico de aglomeración de vehículos (Jordán, 2009). Para calcular la media/ día y media/anual de visitantes durante el periodo estival, se han contabilizado el número total de vehículos que acceden al Parque, así como el número de ocupantes. También se ha contabilizado el número de usuarios del servicio de autobuses lanzadera.

\section{RESULTADOS Y DISCUSIÓN}

\subsection{Recursos para la gestión, el mantenimiento y servicios turísticos}

El Parque Regional de Calblanque, Monte de las Cenizas y Peña del Águila cuenta con un equipo de profesionales que, bajo la coordinación del Director-Conservador del Parque trabajan por la gestión, mantenimiento y conservación de este espacio natural protegido.

El personal de la administración regional que dedica parte de su jornada laboral al Parque (Tabla 1) se vio afectado por la crisis económica, con un descenso significativo a partir de 2012, alcanzando unos mínimos en 2014, viéndose reducido el tiempo de dedicación por parte de la Dirección del Parque, el Uso Público y los Agentes de Medio Ambiente, dedicación que se ha podido recuperar en gran medida en 2015, casi al nivel de dedicación previa a 2012, excepto el tiempo empleado en el Parque por los Agentes Medioambientales.

Tabla 1

PERSONAL DE LA ADMINISTRACIÓN REGIONAL ADSCRITO PARCIALMENTE AL PARQUE. SUMA DE DEDICACIONES PARCIALES

\begin{tabular}{|l|c|c|c|c|c|c|}
\hline Categoría & $\mathbf{2 0 1 0}$ & $\mathbf{2 0 1 1}$ & $\mathbf{2 0 1 2}$ & $\mathbf{2 0 1 3}$ & $\mathbf{2 0 1 4}$ & $\mathbf{2 0 1 5}$ \\
\hline Dirección & - & 0,45 & 0,35 & 0,35 & 0,35 & 0,40 \\
\hline Administración & - & 0,15 & 0,15 & 0,15 & 0,15 & 0,15 \\
\hline Uso Público & - & 0,25 & 0,20 & 0,20 & 0,15 & 0,15 \\
\hline Otras Unidades OREP* & - & 0,20 & 0,20 & 0,20 & 0,20 & 0,20 \\
\hline Otros Servicios DGMA** & - & 0,40 & 0,40 & 0,40 & 0,40 & 0,40 \\
\hline Agentes Medioambientales & - & 1,50 & 0,75 & 0,75 & 0,75 & 1,15 \\
\hline Total dedicación completa & - & $\mathbf{2 , 9 5}$ & $\mathbf{2 , 0 5}$ & $\mathbf{2 , 0 5}$ & $\mathbf{2 , 0 0}$ & $\mathbf{2 , 4 5}$ \\
\hline
\end{tabular}

*OREP: Oficina Regional de Espacios Protegidos/**DGMA: Dirección General de Medio Ambiente. Fuente: Biocyma (2011); Dirección General de Medio Ambiente (2012a, 2013a y 2014a) y OISMA (2015a)

Complementando el trabajo del equipo propio del Parque, los servicios transversales de la administración, se encargan de realizar las tareas específicas y sobre el terreno que le 
corresponden a cada unidad (Tabla 2). El Programa de Mantenimiento y Limpieza destaca por ser el único servicio que dispone durante todo el periodo de estudio de una persona dedicada en exclusividad al Parque, por el contrario, hay dos programas que han dejado de disponer de personal a lo largo de 2011 y 2012: voluntariado ambiental y el de la Red de Áreas de la Naturaleza. Mientras que las actividades del primero son desarrolladas, al menos en parte, por diferentes Organizaciones No Gubernamentales, el segundo ha dejado de funcionar.

El personal de servicios externos se vio reducido de forma drástica en 2012, con una recuperación progresiva hasta casi volver a alcanzar en 2015 el mismo nivel de dedicación que en 2011.

Tabla 2

PERSONAL ADSCRITO A SERVICIOS BÁSICOS EXTERNOS

\begin{tabular}{|l|c|c|c|c|c|c|}
\hline Categoría & $\mathbf{2 0 1 0}$ & $\mathbf{2 0 1 1}$ & $\mathbf{2 0 1 2}$ & $\mathbf{2 0 1 3}$ & $\mathbf{2 0 1 4}$ & $\mathbf{2 0 1 5}$ \\
\hline Mantenimiento y limpieza & - & 1 & 1 & 1 & 1 & 1 \\
\hline Gestión y conservación & - & 0,9 & 0,60 & 0,70 & 0,70 & 0,70 \\
\hline Información y atención visitante & - & 2,5 & 2,50 & 2,50 & 2,52 & 2,70 \\
\hline Prevención selvícola & - & & 0.30 & 0,48 & 0,48 & 0,48 \\
\hline Voluntariado ambiental & - & 0,3 & 0,20 & 0 & 0 & 0 \\
\hline Red Aulas de Naturaleza & - & 0,3 & 0 & 0 & 0 & 0 \\
\hline Total dedicación completa & Sin datos & $\mathbf{5 , 0 0}$ & $\mathbf{2 , 6 0}$ & $\mathbf{4 , 6 8}$ & $\mathbf{4 , 7 0}$ & $\mathbf{4 , 8 8}$ \\
\hline
\end{tabular}

Fuente: Biocyma (2011); Dirección General de Medio Ambiente (2012a, 2013a y 2014a) y OISMA (2015a).

Por tanto, la suma de las dedicaciones parciales muestra que las tareas de conservación y gestión del Parque ha descendido de unas 8 personas en 2011 a 7 personas en 2015 , entre el personal de la administración regional y el contratado externo, con una mayor dedicación a las tareas de información y atención al visitante, vigilancia y mantenimiento y limpieza, servicios que no han sufrido variaciones significativas durante el periodo de estudio.

El Parque tiene a disposición de los visitantes una red de instalaciones y servicios de uso público y turístico (Tabla 3).

Tabla 3

RECURSOS MATERIALES

\begin{tabular}{|l|l|}
\hline TIPO INSTALACIÓN & \multicolumn{1}{c|}{ EQUIPAMIENTO } \\
\hline $\begin{array}{l}\text { Información, atención al visitante y } \\
\text { comunicación social }\end{array}$ & $\begin{array}{l}\text { Punto de Información y Gestión "Las Cobaticas" } \\
\text { Punto de Información Aparcamiento Disuasorio }\end{array}$ \\
\hline Área de Acampada & Calblanque \\
\hline
\end{tabular}




\begin{tabular}{|l|l|}
\hline TIPO INSTALACIÓN & \multicolumn{1}{|c|}{ EQUIPAMIENTO } \\
\hline Áreas Recreativas & $\begin{array}{l}\text { Área Recreativa Grande (municipal) } \\
\text { Área recreativa La Cala (gestión privada) }\end{array}$ \\
\hline Miradores & $\begin{array}{l}\text { Mirador Punta Negra } \\
\text { Mirador de Playa Larga } \\
\text { Mirador Batería de las Cenizas } \\
\text { Mirador El Lastre-Casas del Faro }\end{array}$ \\
\hline Observatorios & 2 observatorios ornitológicos en las Salinas del Rasall \\
\hline Senderos señalizados & $\begin{array}{l}\text { Sendero circular al Cabezo de la Fuente PR-MU1 } \\
\text { Sendero del Monte de las Cenizas-PR-MU2 } \\
\text { Sendero del Mirador de Punta Negra } \\
\text { Senda Botánica Arboretum } \\
\text { Calzada Romana } \\
\text { Sendero de acceso a playas Larga-Negrete }\end{array}$ \\
\hline Estacionamientos & $\begin{array}{l}\text { Estacionamiento el Atochar } \\
\text { Estacionamientos playas: Negrete, Larga, Calblanque, } \\
\text { Arturo y Magre } \\
\text { Punto Información y Gestión “Las Cobaticas" } \\
\text { Estacionamiento disuasorio junto a Vía Rápida } \\
\text { Estacionamiento Fuente Grande } \\
\text { Estacionamiento La Cala }\end{array}$ \\
\hline
\end{tabular}

Fuente: OISMA (2015a).

El presupuesto anual destinado al funcionamiento de los servicios básicos del Parque resulta estable, con una ligera tendencia creciente en todos los capítulos, excepto el de vigilancia y extinción de incendios forestales que se mantiene inalterado durante todo el periodo y el Programa de información, atención al visitante y comunicación social que se incrementa en 2014 y 2015 (Tabla 4).

\section{Tabla 4 \\ FUNCIONAMIENTO DE LOS SERVICIOS BÁSICOS}

\begin{tabular}{|l|c|c|c|c|c|c|}
\hline \multirow{2}{*}{\multicolumn{1}{|c|}{ Servicio }} & \multicolumn{7}{c|}{ Inversión (en €) } \\
\cline { 2 - 8 } & $\mathbf{2 0 1 0}$ & $\mathbf{2 0 1 1}$ & $\mathbf{2 0 1 2}$ & $\mathbf{2 0 1 3}$ & $\mathbf{2 0 1 4}$ & $\mathbf{2 0 1 5}$ \\
\hline Mantenimiento y limpieza & 35.153 & 53.935 & 53.705 & 63.478 & 80.172 & 68.593 \\
\hline $\begin{array}{l}\text { Vigilancia y extinción } \\
\text { incendios forestales }\end{array}$ & Sin datos & Sin datos & 20.334 & 20.334 & 20.334 & 20.334 \\
\hline $\begin{array}{l}\text { Programa de información, } \\
\text { atención al visitante y } \\
\text { comunicación social }\end{array}$ & Sin datos & Sin datos & 89.491 & 89.491 & 90,275 & 94.590 \\
\hline TOTAL & - & - & 181.428 & 173.304 & 190.782 & 183.518 \\
\hline
\end{tabular}

Fuente: Biocyma (2010 y 2011); Dirección General de Medio Ambiente (2012a, 2013a y 2014a) y OISMA (2015a). 


\subsection{Mantenimiento y limpieza}

Estas actividades de carácter básico, se enmarcan en el programa del Servicio integral de mantenimiento y limpieza de la red de infraestructuras y áreas de uso público y defensa del medio natural de la Región de Murcia, teniendo como objetivo, el mantenimiento y adecuado estado de conservación de las infraestructuras y áreas de uso público existentes en el medio natural y en especial, en la Red Natura 2000, así como a las infraestructuras básicas destinadas a la defensa forestal.

En este Parque Regional, sus funciones se centran en la recogida de residuos, de los equipamientos exteriores: áreas recreativas, zonas de acampada, miradores, apartaderos, aparcamientos, senderos, itinerarios y lugares de interés más visitados y de las principales vías de comunicación en el interior del Parque. Esta actividad está permanentemente supervisada por un coordinador (Tabla 5). En la actualidad existe una brigada formada por una persona, destinada de forma exclusiva al Parque Regional de forma que realiza rutas semanales de limpieza.

El resultado refleja una tendencia decreciente en el volumen de residuos urbanos retirados de los exteriores del interior del Parque, que se ha reducido entre el periodo 2011-2015 en un 42,5\%, probablemente favorecido por las actuaciones de control de accesos en el periodo estival, que durante el periodo estival, momento de mayor afluencia al Parque, ha favorecido un descenso significativo en el número de personas y de vehículos que acceden al Parque.

Tabla 5

MANTENIMIENTO Y LIMPIEZA

\begin{tabular}{|l|c|c|c|c|c|c|}
\hline \multirow{2}{*}{ Servicio } & \multicolumn{5}{|c|}{ Residuos sólidos urbanos (Kg) en el entorno del Parque } \\
\cline { 2 - 7 } & $\mathbf{2 0 1 0}$ & $\mathbf{2 0 1 1}$ & $\mathbf{2 0 1 2}$ & $\mathbf{2 0 1 3}$ & $\mathbf{2 0 1 4}$ & $\mathbf{2 0 1 5}$ \\
\hline Residuos Sólidos Urbanos (Kg) & - & 10.848 & 7.970 & 8.060 & 7.370 & 6.240 \\
\hline $\begin{array}{l}\text { Actuaciones de Mantenimiento } \\
\left(\mathrm{n}^{\mathrm{o}} \text { horas) }\right.\end{array}$ & - & 824 & 309 & 185 & 550 & 434 \\
\hline
\end{tabular}

Fuente: Biocyma (2010 y 2011); Dirección General de Medio Ambiente (2012a, 2013a y 2014a) y OISMA (2015a).

Se dispone de una brigada de mantenimiento a nivel Regional que resuelve todas las incidencias y solicitudes que les deriva el coordinador del servicio (Tabla 6). No dispone de un cuadrante regular sino que va resolviendo incidencias conforme a la prioridad de actuación, orden de llegada y otros criterios. El número de actuaciones en este Parque Regional es irregular, pero con un incremento significativo sobre todo en 2014, año en el que se renovaron un número importante de infraestructuras y señales, mientras que en 2015 las actuaciones de mantenimiento se emplearon sobre todo en el mantenimiento del Centro de Visitantes y punto de información. 
Tabla 6

ACTUACIONES DE MANTENIMIENTO RESUELTAS EN EL PARQUE (No DE HORAS DE TRABAJO)

\begin{tabular}{|l|c|c|c|c|c|c|}
\hline Tipo de Incidencia & $\mathbf{2 0 1 0}$ & $\mathbf{2 0 1 1}$ & $\mathbf{2 0 1 2}$ & $\mathbf{2 0 1 3}$ & $\mathbf{2 0 1 4}$ & $\mathbf{2 0 1 5}$ \\
\hline $\begin{array}{l}\text { Apoyo a la gestión y a } \\
\text { actividades especiales }\end{array}$ & - & - & 55 & 16 & 19 & 20 \\
\hline $\begin{array}{l}\text { Limpieza y retirada puntual de } \\
\text { residuos }\end{array}$ & - & - & 12 & 0 & 44 & 19 \\
\hline $\begin{array}{l}\text { Mantenimiento de } \\
\text { infraestructuras y señales en el } \\
\text { medio natural }\end{array}$ & - & - & 79 & 58 & 385 & 199 \\
\hline $\begin{array}{l}\text { Mantenimiento de C. Visitantes, } \\
\text { Punto de Información, A. } \\
\text { Naturaleza y similares }\end{array}$ & - & - & 0 & 111 & 102 & 199 \\
\hline TOTAL & - & - & 309 & 185 & 550 & 456 \\
\hline
\end{tabular}

Fuente: Biocyma (2010 y 2011); Dirección General de Medio Ambiente (2012a, 2013a y 2014a) y OISMA (2015a).

\subsection{Prevención de incendios forestales}

Las labores de vigilancia, prevención y extinción de incendios en el ámbito del Parque Regional de Calblanque las desarrolla una brigada de 5 componentes ubicada en Cartagena y que cubre la Comarca de Cartagena. Los recursos humanos y materiales de este servicio pertenecen en gran medida al Servicio de prevención selvícola y defensa contra incendios de las masas forestales de la Región de Murcia.

En el interior del Parque Regional no se localizan medios de vigilancia y extinción, por lo que estas labores se realizan con los siguientes medios:

- Malla eco: un punto de vigilancia fijo de incendios forestales situado en la Sierra de las Herrerías, activo durante 16 horas durante 6,5 meses en el año 2012.

- BRIFOR Cartagena: un retén terrestre, compuesto por 5 personas/día durante 12 meses, dirigidos por un agente medioambiental, provistos de un camión autobomba todoterreno y herramientas de extinción y con base en las instalaciones sitas en Tentegorra.

Desde el mes de julio de 2009 se encuentra en funcionamiento el Centro de Coordinación Forestal en el Valle y Carrascoy (CECOFOR) que apoya en la coordinación de Incendios Forestales y demás tareas realizadas por el cuerpo de agentes medio ambientales. También participan de forma activa en las labores de extinción, en caso de que fuese necesario, las Brigadas Helitransportadas de la Base de Alcantarilla, Zarcilla de Ramos y Sierra de la Pila. 
Además de la extinción de incendios, las brigadas tienen la misión de mantener en buen estado los cortafuegos y fajas auxiliares, por lo que periódicamente se procede a su desbroce y aclareo.

Para el periodo 2012-2015 ha descendido en un 91,2 \% la superficie total intervenida, pasando de 9,12 ha en 2012 a 0,8 ha en 2015 (Tabla 7).

Tabla 7

ACTUACIONES DE PREVENCIÓN DE INCENDIOS FORESTALES

\begin{tabular}{|l|c|c|c|c|c|c|}
\hline \multirow{2}{*}{ Servicio } & \multicolumn{7}{|c|}{ Superficie manejada (ha) } \\
\cline { 2 - 7 } & $\mathbf{2 0 1 0}$ & $\mathbf{2 0 1 1}$ & $\mathbf{2 0 1 2}$ & $\mathbf{2 0 1 3}$ & $\mathbf{2 0 1 4}$ & $\mathbf{2 0 1 5}$ \\
\hline $\begin{array}{l}\text { Desbroce/clareo faja } \\
\text { auxiliar }\end{array}$ & Sin datos & Sin datos & 7,08 ha & 5,9 ha & 0,9 ha & 0,8 ha \\
\hline $\begin{array}{l}\text { Desbroce/clareo área } \\
\text { cortafuegos }\end{array}$ & Sin datos & Sin datos & 2,04 ha & 5,9 ha & 0 & 0 \\
\hline
\end{tabular}

Fuente: Biocyma (2010 y 2011); Dirección General de Medio Ambiente (2012a, 2013a y 2014a) y OISMA (2015a).

\subsection{Información, atención al visitante y comunicación social}

El equipo de Información del Servicio de información y atención al visitante en el Parque Regional de Calblanque, Monte de las Cenizas y Peña del Águila, se compone de dos informadoras-guías y una coordinadora que al mismo tiempo dirige el Programa de Información del Parque Regional de las Salinas y Arenales de San Pedro del Pinatar. Además, a finales del 2014 se incorpora al equipo de información una informadora-guía que presta apoyo a los Parques Regionales de Calblanque y Salinas de San Pedro durante los fines de semana.

Desde 2010 el número de visitantes atendidos por el punto de información fluctúa según los años debido a los diferentes escenarios que se plantean desde el Control de Accesos situado a la entrada del Parque.

En el año 2011 se pone en funcionamiento un servicio de autobuses que traslada a los visitantes desde la entrada del Parque a las playas directamente sin realizar paradas en el Punto de Información de las Cobaticas (Figura 3), por lo que se produce los fines de semana del periodo estival un descenso de personas atendidas.

Sin embargo, en el año 2012, se contabilizan como visitantes atendidos los que acceden al autobús que conectan con las playas, ya que el Servicio de Atención al Visitante es quien los atiende en el Punto de Información adicional situado temporalmente en la entrada del Parque y quien se encarga de expender los tickets del autobús.

Esta tarea no la realiza el Servicio de Atención al Visitante en el año 2013, por lo que desciende el número de visitantes atendidos ese año, siendo similar al dato de 2010, ya que continúa siendo difícil acceder al Punto de Información de la Cobaticas los fines de semana debido al itinerario del servicio de autobuses que va directo desde la entrada del Parque a las playas. 
En el año 2014 se desarrolla una medida disuasoria diferente a las realizadas en años anteriores, que supone el pago en los aparcamientos de las playas del Parque Regional. Para su desarrollo se cuenta con personal encargado del cobro de la tasa por aparcar. Los visitantes aprovecharon su presencia para hacer las consultas sobre el Parque, esto hace que disminuyan el número de visitas al Centro de Visitantes, por la comodidad del visitante que se conforma con la información obtenida por el personal de los aparcamientos.

Figura 3

\section{LOCALIZACIÓN DEL CONTROL DE ACCESOS, PUNTO DE INFORMACIÓN Y OTRAS ÁREAS DE INTERÉS}

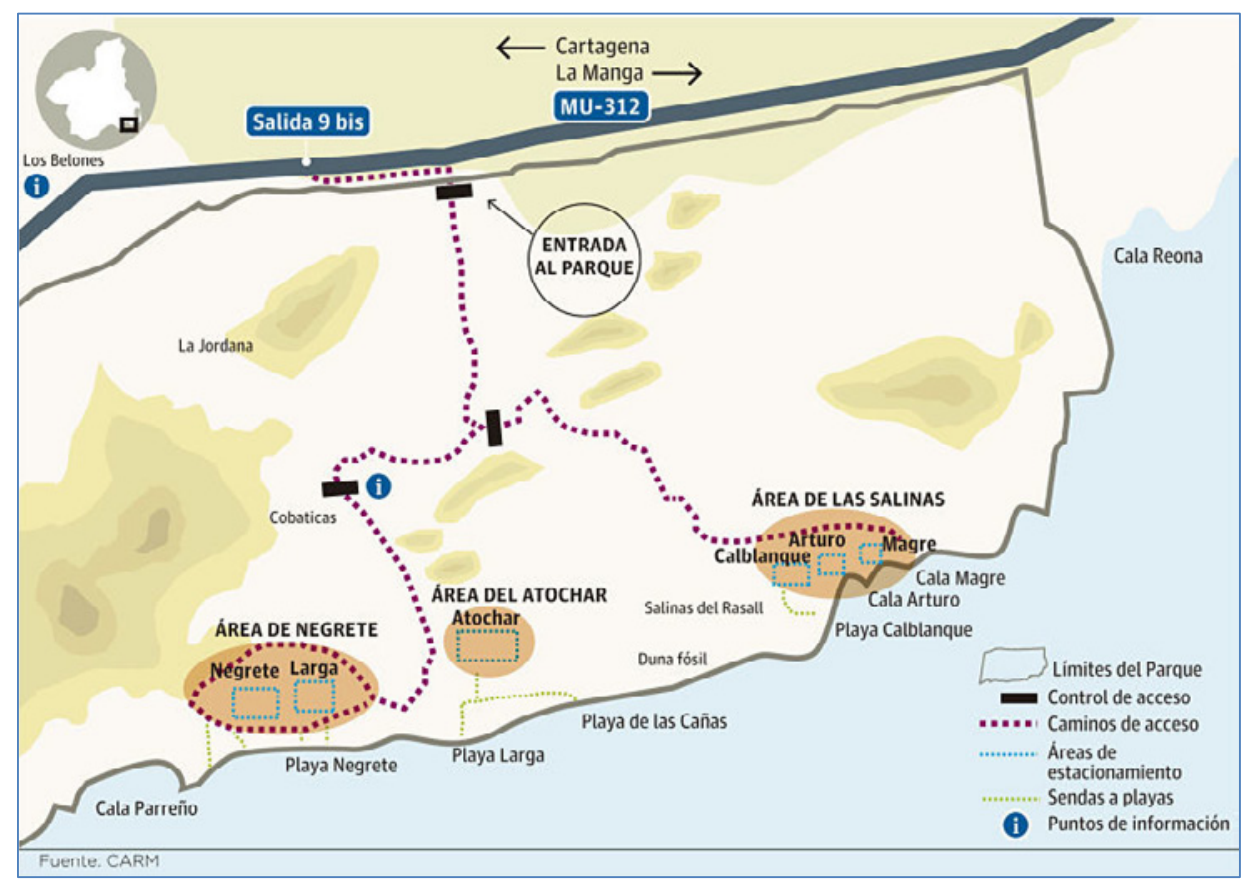

Otro motivo por el que disminuyen los visitantes en 2014 se debe al número de participantes en actividades especiales, ya que durante ese año se llevan a cabo más rutas y talleres donde el número máximo de participantes que pueden inscribirse es de 30 personas, frente a otro tipo de actividades que fueron más numerosas en 2013 como las exposiciones, a las que puede asistir un número mayor de participantes por no ser necesario un guía.

En el año 2015, el número de visitantes atendidos sufre un descenso respecto a años anteriores, pasando de 10.437 visitantes atendidos en 2013 y 8.889 visitantes atendidos en 2014, a un mínimo en el periodo 2010-2016 de 6.946 visitantes atendidos en 2015. Esto se debe a que el punto de información del Centro de Visitantes permanece cerrado 
para llevar a cabo obras de remodelación y a los dos meses que ha permanecido cortado el acceso principal al Parque (Figura 4).

El incremento en el número de visitantes atendidos en 2016 se debe a que en ese año el personal del servicio de visitantes se traslada a la entrada del Parque para asumir las funciones de información en el Control de Accesos que anteriormente era asumido por su propio personal.

\section{Figura 4 \\ NÚMERO DE PERSONAS INFORMADAS}

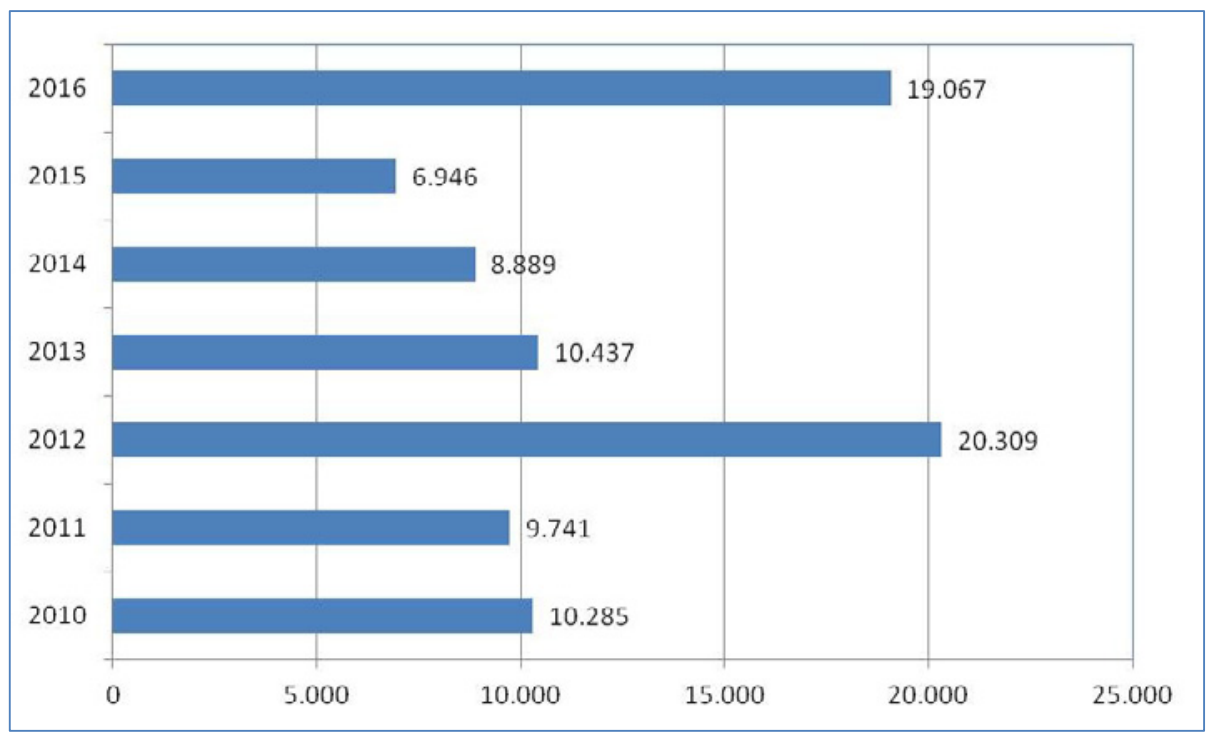

Fuente: Dirección General de Medio Ambiente (2010, 2011, 2012b, 2013b y 2014b) y de OISMA (2015b, 2016b y 2017).

Los visitantes atendidos en mayor número (37,8\% de media 2010-2016) proceden de otras Comunidades Autónomas (Tabla 8), mientras que los de otros municipios de la Región de Murcia constituyen el 26,1 \%, debido principalmente a las visitas guiadas y otras actividades que se realizan, cuyos participantes provienen de la Región de Murcia, pero fuera de los términos municipales de Cartagena y La Unión, que son los municipios en los que se encuentra el espacio protegido. También destaca el porcentaje de visitantes extranjeros (20,6 \% de media 2010-2016), en su mayor parte británicos. Finalmente, los visitantes procedentes de los municipios del Parque representan el menor porcentaje $(14,1$ $\%$ de media 2010-2016), probablemente porque conocen el entorno y no pasan por el Centro de Visitantes situado en el Punto de Información de las Cobaticas. 


\section{Tabla 8 \\ PROCEDENCIA DE LOS VISITANTES QUE ACCEDEN AL CENTRO DE VISITANTES}

\begin{tabular}{|l|c|c|c|c|c|c|c|}
\hline & $\mathbf{2 0 1 0}$ & $\mathbf{2 0 1 1}$ & $\mathbf{2 0 1 2}$ & $\mathbf{2 0 1 3}$ & $\mathbf{2 0 1 4}$ & $\mathbf{2 0 1 5}$ & $\mathbf{2 0 1 6}$ \\
\hline Sin identificar procedencia & 0 & 0 & 10.563 & 223 & 247 & 133 & 193 \\
\hline Municipios del Parque & 996 & 984 & 1.460 & 1.638 & 1.325 & 1.265 & 1.534 \\
\hline $\begin{array}{l}\text { Otros municipios de la } \\
\text { Región }\end{array}$ & 1.225 & 1.144 & 2.794 & 3138 & 2.889 & 2.420 & 4.995 \\
\hline Otras Comunidades & 3.095 & 2.877 & 3.712 & 3.423 & 2.812 & 2.019 & 9.526 \\
\hline Extranjeros & 2.125 & 1.840 & 1.780 & 2.015 & 1.616 & 1.109 & 2.819 \\
\hline TOTAL VISITANTES & 7.441 & 6.845 & 20.309 & 10.437 & 8.889 & 6.946 & 19.067 \\
\hline
\end{tabular}

Fuente: Dirección General de Medio Ambiente (2010, 2011, 2012b, 2013b y 2014b) y de OISMA (2015b, 2016b y 2017).

\subsection{Autorizaciones de uso público y turístico}

Una de las funciones del equipo gestor del Parque es dar respuesta a las solicitudes de todo tipo de actividades que plantean realizar en su interior. La demanda de actividades en interior del Parque presenta una tendencia creciente hasta 2015, año en el que se produce un descenso importante de solicitudes, debido en parte a que ese año se deja de ofertar al público el área de acampada por el déficit de infraestructuras.

Además de la acampada, la actividad más demandada en el Parque Regional es la realización de maniobras militares (Tabla 9), que se autorizan con el condicionante de que se cumpla la normativa de conservación, por lo que los impactos en todo caso son mínimos.

Tabla 9

AUTORIZACIONES DE USO PÚBLICO Y TURÍSTICO

\begin{tabular}{|l|c|c|c|c|c|c|}
\hline \multirow{2}{*}{ Servicio } & \multicolumn{7}{|c|}{ Autorizaciones de uso público } \\
\cline { 2 - 7 } & $\mathbf{2 0 1 0}$ & $\mathbf{2 0 1 1}$ & $\mathbf{2 0 1 2}$ & $\mathbf{2 0 1 3}$ & $\mathbf{2 0 1 4}$ & $\mathbf{2 0 1 5}$ \\
\hline Acampada & 2 & 21 & 39 & 25 & 36 & 11 \\
\hline Audiovisual & 4 & 12 & 7 & 4 & 5 & 9 \\
\hline Ciclismo & 1 & 6 & 7 & 3 & 1 & 1 \\
\hline Educación Ambiental & 7 & 10 & 2 & 5 & 14 & 8 \\
\hline Investigación & & & 3 & 1 & 2 & 3 \\
\hline Militar & 8 & 10 & 8 & 0 & 20 & 11 \\
\hline Montañismo & 1 & 1 & 2 & 2 & 3 & 3 \\
\hline Senderismo & 4 & 9 & 8 & 4 & 3 & 3 \\
\hline Otros & 5 & 1 & 5 & 2 & 5 & 3 \\
\hline TOTAL & $\mathbf{3 2}$ & $\mathbf{5 0}$ & $\mathbf{8 1}$ & $\mathbf{5 7}$ & $\mathbf{8 9}$ & $\mathbf{5 2}$ \\
\hline
\end{tabular}

Fuente: Dirección General de Medio Ambiente (2010, 2011, 2012b, 2013b y 2014b) y de OISMA (2015b, 2016b y 2017). 


\subsection{Actuaciones de gestión en el Parque}

La mayor parte de la inversión de las actuaciones de gestión proactiva que se llevan a cabo en el Parque Regional, están relacionadas con la conservación del patrimonio natural y cultural y con inversiones en Infraestructuras y defensa del medio natural. Para el periodo 2010-2015 se han destinado un mínimo de $228.917 €$ en 2011 y un máximo de $673.751 €$ en 2013 (Tabla 10).

En 2010 las inversiones en actuaciones de conservación se han centrado en las salinas del Rasall, tratamientos silvícolas en los pinares del Monte de las Cenizas y eliminación de plantas alóctonas invasoras en el entorno las antiguas baterías militares de la Chapa y las Cenizas.

En 2011 las inversiones en conservación se han dirigido a la mejora de las salinas del Rasall y restauración de hábitats costeros, este último proyecto financiado por la Obra Social de la Caixa.

En 2012 la mayor parte de las actuaciones están relacionadas con la conservación del patrimonio natural y cultural, la inversión ha sido destinada en gran parte a la adecuación biológica de las Salinas del Rasall y a la ordenación de accesos para la protección de hábitat.

En 2013 la inversión en conservación del patrimonio natural y cultural ha sido destinada en gran parte a la adecuación biológica de las Salinas del Rasall y a la ordenación de accesos para la protección de hábitat. Otra actuación ha sido la dirigida a la restauración de la zona de Atamaría incendiada en 2011. Las inversiones realizadas en infraestructuras y defensa del medio natural han ido destinadas principalmente al acondicionamiento y mejora de la red viaria, mientras que las realizadas en equipamientos y uso público se concentran principalmente en la mejora de las zonas de estacionamiento del Parque Regional.

En 2014 la mayor parte de esta inversión se corresponde con la puesta en marcha del proyecto LIFE “Conservación del Hábitat 9570*, Bosques de Tetraclinis articulata en el continente europeo", hábitats prioritarios que pretenden conservar éste endemismo iberoafricano (Dirección General de Medio Natural, 2018). Las inversiones realizadas en infraestructuras y defensa del medio natural han ido destinadas principalmente al acondicionamiento y mejora de la red viaria, mientras que las realizadas en equipamientos y uso público se dirigen principalmente en la adecuación de instalaciones para personas con discapacidad.

En 2015 se ha invertido en las actuaciones del proyecto LIFE "Conservación del Hábitat 9570*, Bosques de Tetraclinis articulata en el continente europeo” y en las obras de hormigonado del camino principal de acceso al Parque Regional.

\section{Tabla 10 \\ INVERSIÓN EN ACTUACIONES DE GESTIÓN Y CONSERVACIÓN}

\begin{tabular}{|l|c|c|c|c|c|c|}
\hline \multirow{2}{*}{ Servicio } & \multicolumn{7}{|c|}{ Inversiones en actuaciones de gestión (€) } \\
\cline { 2 - 7 } & $\mathbf{2 0 1 0}$ & $\mathbf{2 0 1 1}$ & $\mathbf{2 0 1 2}$ & $\mathbf{2 0 1 3}$ & $\mathbf{2 0 1 4}$ & $\mathbf{2 0 1 5}$ \\
\hline $\begin{array}{l}\text { Conservación patrimonio } \\
\text { natural y cultural }\end{array}$ & 161.287 & 203.567 & 188.409 & 520.938 & 187.346 & 303.303 \\
\hline $\begin{array}{l}\text { Infraestructuras y defensa } \\
\text { del medio natural }\end{array}$ & 356.131 & 17.480 & 27.708 & 52.007 & 72.000 & 248.522 \\
\hline
\end{tabular}




\begin{tabular}{|c|c|c|r|r|r|r|}
\hline \multirow{2}{*}{ Servicio } & \multicolumn{6}{|c|}{ Inversiones en actuaciones de gestión (€) } \\
\cline { 2 - 7 } & $\mathbf{2 0 1 0}$ & $\mathbf{2 0 1 1}$ & $\mathbf{2 0 1 2}$ & $\mathbf{2 0 1 3}$ & $\mathbf{2 0 1 4}$ & $\mathbf{2 0 1 5}$ \\
\hline $\begin{array}{l}\text { Investigación, estudio y } \\
\text { participación social }\end{array}$ & 11.190 & 0 & 0 & 0 & 8.500 & 2.500 \\
\hline TOTAL & $\mathbf{6 0 9 . 2 5 8}$ & $\mathbf{2 2 8 . 9 1 7}$ & $\mathbf{2 5 2 . 5 6 9}$ & $\mathbf{6 7 3 . 7 5 1}$ & $\mathbf{3 2 9 . 7 6 4}$ & $\mathbf{5 8 7 . 4 0 5}$ \\
\hline
\end{tabular}

Fuente: Biocyma (2010 y 2011); Dirección General de Medio Ambiente (2012a, 2013a y 2014a) y OISMA (2015a).

\subsection{Ordenación de acceso turístico}

La Comunidad Autónoma de la Región de Murcia pone en marcha cada verano desde 2010 un dispositivo para ordenar el acceso y estacionamiento de vehículos a motor en este espacio natural, con el objetivo de minimizar las afecciones a los hábitats litorales (Tabla 11). Entre los años 2010 y 2013 se establecen las primeras limitaciones de acceso a los estacionamientos: durante los días entre semana se permite el acceso de vehículos a motor hasta alcanzar la capacidad de acogida de los aparcamientos, mientras que los fines de semana se pone un servicio de autobuses gratuito a disposición de los visitantes, no permitiendo el acceso de vehículos a motor. Para ello, previamente se calculó la capacidad máxima de los aparcamientos en 466 vehículos, que al año siguiente sería reajustada a un total de 528 plazas de aparcamiento, que corresponde a un total de 1.584 personas, considerando que cada vehículo accede con una media de 3 personas.

\section{Tabla 11}

\section{CAPACIDAD DE ACOGIDA ADMISIBLE EN LOS APARCAMIENTOS}

\begin{tabular}{|l|c|}
\hline Aparcamiento & Plazas \\
\hline Cala Magre & 40 \\
\hline Cala Arturo & 25 \\
\hline Playa Calblanque & 40 \\
\hline Playa Las Cañas & 83 \\
\hline Aparcamiento cubierto & 150 \\
\hline Playa Larga & 80 \\
\hline Playa Negrete & 110 \\
\hline Total plazas disponibles playas & 528 \\
\hline
\end{tabular}

Fuente: Jordán (2009).

Para resolver el problema de superación de la capacidad de carga, se plantearon, entre otras, las siguientes medidas:

- Limitación de entrada de vehículos a un máximo de 528 coches de modo simultáneo en los aparcamientos. 
- Adecuar un mecanismo alternativo de acceso a las playas para aquellos visitantes que no se les permita entrar con su vehículo propio. Se propone el empleo de autobuses.

- Habilitar un aparcamiento alternativo disuasorio para estacionar aquellos vehículos que no puedan acceder hasta la zona de playas.

- Delimitación y señalización de aparcamientos, de modo que los vehículos no invadan aquellas áreas ocupadas por la vegetación natural.

- Las infraestructuras destinadas al control y ordenación de los visitantes a las playas, serán de carácter temporal, siendo retiradas cuando finalice la campaña de verano.

- Plan de divulgación de la ordenación de los accesos al parque mediante colocación de carteles informativos e interpretativos, divulgación en medios de comunicación, edición de folletos e información a los agentes locales y asociaciones de vecinos de las poblaciones más próximas

Aplicando los criterios anteriores se garantiza que el número de vehículos que ocupa cada aparcamiento (Tabla 12) no provoca problemas de congestión ni atascos, desarrollándose la circulación de vehículos con fluidez, aumentando el grado de satisfacción de los visitantes y un mayor respeto a la vegetación circundante, ya que evita que los vehículos aparquen fuera de la zona reservada a los mismos (Jordán 2009).

En el año 2014, la Entidad de Custodia del Territorio conformada por los principales propietarios de las áreas de estacionamiento del Parque Regional solicita a la Dirección General de Medio Ambiente asumir la gestión de la ordenación del acceso de vehículos a motor a las áreas, tanto privadas como las que están en posesión de la Administración regional. Esa actividad se autoriza por Resolución de 11 de julio de 2014. Pero este sistema generó conflicto con los vecinos y los grupos ecologistas de la Región de Murcia (Ecologistas en Acción y Asociación de Naturalistas del Sureste), los primeros por tener que pagar diariamente si querían acercarse a la playa y los segundos por considerarlo una medida meramente recaudatoria, conflictividad que motivó que este modelo haya sido sustituido por otro en los siguientes años.

En el año 2015, la Dirección General de Medio Ambiente define un sistema de ordenación de accesos que se extiende durante 72 días, del 27 de junio al 6 de septiembre. Durante este periodo se permite el acceso de vehículos a motor hasta alcanzar la capacidad de acogida admisible de las áreas de estacionamiento (466 vehículos), momento en el cual el acceso a estas áreas no estará permitido. Se establecen tres áreas de estacionamiento, fuera de las cuales no está permitido el estacionamiento. En el Área del Atochar el estacionamiento es gratuito, mientras que en las Áreas de Negrete y de las Salinas, los propietarios pueden establecer tarifas por el estacionamiento.

En el año 2016, la Dirección General del Medio Natural, en colaboración con el Ayuntamiento de Cartagena y de conformidad con los miembros de la Junta Rectora del Parque Regional, impulsa un nuevo modelo de Ordenación de Accesos a las Playas del LIC y Parque Regional de Calblanque que consiste en la puesta en marcha de un servicio de autobuses para el acceso de visitantes a las playas del Parque Regional durante todo el periodo estival, modelo que parece estar dando buenos resultados, al disponer del apoyo 
de los vecinos y grupos ecologías, así como tener un alto grado de aceptación entre los visitantes y turistas del Parque.

Tabla 12

ORDENACIÓN DE ACCESOS (2010-2017)

\begin{tabular}{|c|c|c|c|c|c|c|c|c|}
\hline \multirow{2}{*}{ Año } & \multirow{2}{*}{ Días } & \multirow{2}{*}{$\begin{array}{c}\mathbf{N}^{\mathbf{0}} \text { de } \\
\text { visitantes } \\
\text { por } \\
\text { vehículo }\end{array}$} & \multirow{2}{*}{$\begin{array}{c}\text { Número } \\
\text { vehículos } \\
\text { 15/07- } \\
31 / 08\end{array}$} & \multirow{2}{*}{$\begin{array}{c}\text { Media/día } \\
\text { entrada } \\
\text { visitantes } \\
\text { 16/07-31/08 }\end{array}$} & \multicolumn{2}{|c|}{$\begin{array}{c}\begin{array}{c}\text { Usuarios servicio } \\
\text { autobuses }\end{array} \\
\end{array}$} & \multicolumn{2}{|c|}{$\begin{array}{c}\mathbf{N}^{0} \text { pases población } \\
\text { local }\end{array}$} \\
\hline & & & & & $\begin{array}{c}\text { Días } \\
\text { servicio }\end{array}$ & Personas & Emitidos & Usados \\
\hline 2009 & 0 & - & - & 4.289 & 0 & - & 0 & 0 \\
\hline 2010 & 45 & - & - & - & 12 & 5.981 & 353 & 60 \\
\hline 2011 & 45 & 2,76 & - & - & 12 & 11.022 & 538 & 235 \\
\hline 2012 & 45 & 2,79 & - & - & 12 & 10.234 & Sin datos & Sin datos \\
\hline 2013 & 45 & 2,83 & 35.247 & 2.344 & 12 & 10.393 & Sin datos & Sin datos \\
\hline 2014 & 72 & 2,81 & 28.100 & 1.712 & 0 & 0 & Sin datos & Sin datos \\
\hline 2015 & 72 & 2,79 & 35.799 & 2.179 & 0 & 0 & Sin datos & Sin datos \\
\hline 2016 & 72 & 2,41 & 4.730 & 1.043 & 72 & 44.485 & 422 & 303 \\
\hline 2017 & 79 & 2,49 & 3.887 & 1.008 & 79 & 50.363 & 504 & 316 \\
\hline
\end{tabular}

Fuente: Biocyma (2010 y 2011); Dirección General de Medio Ambiente (2012b, 2013b y 2014b) y OISMA (2015b).

\section{CONCLUSIONES}

El interés ecológico, turístico, recreativo y cultural del Parque Regional de Calblanque, Monte de las Cenizas y Peña de Águila lo convierten en un enclave donde la administración ambiental destina un importante esfuerzo de regulación de usos para su conservación, en el que dedican su jornada laboral unas 7 personas entre personal de la administración regional y personal externo, con un presupuesto anual que supera los 600 mil euros anuales para el funcionamiento de los servicios básicos, mantenimiento de las infraestructuras y equipamientos de uso público y la inversión en actuaciones de gestión y conservación, entre las que destacan las actuaciones de conservación de los hábitats prioritarios que forman los bosques del endemismo iberoafricano Tetraclinis articulata y la inversión en la recuperación y mantenimiento de las Salinas del Rasall, para la conservación de las especies asociadas a ambientes acuáticos salinos.

Las inversiones realizadas en infraestructuras han ido destinadas principalmente al acondicionamiento y mejora de la red viaria, mientras que las realizadas en equipamientos y uso público sobre todo a la adecuación de instalaciones para personas con discapacidad.

La ordenación de accesos durante el periodo estival a partir de 2010, ha ido fluctuando con la experimentación de diferentes modelos, hasta comprobar que el modelo más eficaz ha sido un sistema de autobuses que recoge a los visitantes desde un aparcamiento situado a la entrada del Parque y los lleva hasta las playas, evitando así el colapso de los aparcamientos cercanos a las playas, el exceso de vehículos por los caminos de acceso, los 
accidentes de tráfico y el polvo generado que perjudicaba enormemente a la vegetación del entorno.

\section{BIBLIOGRAFÍA}

ALCARÁZ, F., BARREÑA, J.A., CLEMENTE, C.M., GONZÁLEZ, J.L., RIBERA, D. y RÍOS, S. (2008): Manual de interpretación de los Hábitats naturales y seminaturales de la Región de Murcia. Murcia, Consejería de Agricultura, Agua y Medio Ambiente de la Región de Murcia.

ÁLVAREZ, L. (2016): El uso turístico de los Parques Nacionales. Experiencias internacionales de interés para el Parque Nacional del Teide. Trabajo Fin de Grado. Universidad de La Laguna.

BALLESTEROS PELEGRÍN, G.A. (2014): «El turismo de naturaleza en espacios naturales. El caso del Parque Regional de las Salinas y Arenales de San Pedro del Pinatar». Cuadernos de Turismo, $\mathrm{n}^{\circ} 34$, pp. 33-51

BIOCYMA (2010): Memoria de gestión del Parque Regional Calblanque, Monte de las Cenizas y Peña del Águila. Murcia, Dirección General de Medio Ambiente.

BIOCYMA (2011): Memoria de gestión del Parque Regional Calblanque, Monte de las Cenizas y Peña del Águila. Murcia, Dirección General de Medio Ambiente.

BOO, E. (1995): «Establecimiento de la capacidad de carga. Desarrollo económico compatible: ecoturismo, un manual para organizaciones conservacionistas de América Latina y el Caribe», en The Natural Conservancy. Virginia, Arlington, pp. 34-47.

CONSEJERÍA DE MEDIO AMBIENTE (1994): Decreto N. 9/1994, de 4 de febrero, de constitución y funcionamiento de Juntas Rectoras de Espacios Naturales Protegidos. Región de Murcia.

CONSEJO DE MINISTROS (1994): Inclusión de los embalses de Cordobilla y Malpasillo, albufera de Adra, ría de Eo, Mar Menor, marismas de Santoña y marjal de Pego-Oliva, en la lista del Convenio de Ramsar, relativo a Humedales de Importancia Internacional, especialmente como Hábitat de Aves Acuáticas. Acuerdo del Consejo de Ministros. Madrid.

DIRECCIÓN GENERAL DE MEDIO AMBIENTE (2010): Programa de Información, Atención al Visitante y Comunicación Social del Parque Regional de Calblanque, Monte de las Cenizas y Peña del Águila. Murcia. Comunidad Autónoma de la Región de Murcia.

DIRECCIÓN GENERAL DE MEDIO AMBIENTE (2011): Programa de Información, Atención al Visitante y Comunicación Social del Parque Regional de Calblanque, Monte de las Cenizas y Peña del Águila. Murcia. Comunidad Autónoma de la Región de Murcia.

DIRECCIÓN GENERAL DE MEDIO AMBIENTE (2012a): Memoria de gestión del Parque Regional de Calblanque, Monte de las Cenizas y Peña del Águila. Murcia. Comunidad Autónoma de la Región de Murcia.

DIRECCIÓN GENERAL DE MEDIO AMBIENTE (2012b): Programa de Información, Atención al Visitante y Comunicación Social del Parque Regional de Calblanque, 
Monte de las Cenizas y Peña del Águila. Murcia. Comunidad Autónoma de la Región de Murcia.

DIRECCIÓN GENERAL DE MEDIO AMBIENTE (2013a): Memoria de gestión del Parque Regional de Calblanque, Monte de las Cenizas y Peña del Águila. Murcia. Comunidad Autónoma de la Región de Murcia

DIRECCIÓN GENERAL DE MEDIO AMBIENTE (2013b): Programa de Información, Atención al Visitante y Comunicación Social del Parque Regional de Calblanque, Monte de las Cenizas y Peña del Águila. Murcia. Comunidad Autónoma de la Región de Murcia.

DIRECCIÓN GENERAL DE MEDIO AMBIENTE (2014a): Memoria de gestión del Parque Regional de Calblanque, Monte de las Cenizas y Peña del Águila. Murcia. Comunidad Autónoma de la Región de Murcia.

DIRECCIÓN GENERAL DE MEDIO AMBIENTE (2014b): Programa de Información, Atención al Visitante y Comunicación Social del Parque Regional de Calblanque, Monte de las Cenizas y Peña del Águila. Murcia. Comunidad Autónoma de la Región de Murcia.

DIRECCIÓN GENERAL DE MEDIO NATURAL (1995): Plan de Ordenación de los Recursos Naturales Calblanque, Monte de las Cenizas y Peña del Águila. Región de Murcia, Consejería de Agricultura y Agua, Dirección General del Medio Ambiente, $76 \mathrm{p}$.

DIRECCIÓN GENERAL DE MEDIO NATURAL. http//www.lifetetraclinis.eu [consulta: 27 de abril de 2018].

DÓNIZ-PÁEZ, J., BECERRA-RAMÍREZ, R., GONZÁLEZ-CÁRDENAS, E., GUILLÉNMARTÍN, C. y ESCOBAR-LAHOZ, E. (2010): «Volcanic geomorphosites and sustainable tourism: the example of the La Corona del Lajial Volcanic Complex», en EL Hierro island, Canary, Spain”. 6th Cities on volcanoes. Abstracts volume. 192.

CAVERO-SANCHO, L. (1999): El Parque Regional de Calblanque, Monte de las Cenizas y Peña del Águila. Murcia, Consejería de Agricultura, Agua y Medio Ambiente, 157 p.

EAGLES, F.J. y MCCOOL, F. (2000): Tourism in National Parks and Protected Areas: Planning and Management. UK, CAB International.

EAGLES, P.F.J. (2002): "International trends in park tourism and economics. In: BrodrupNielsen, S. and Munro, N. W. P. Managing Protected Areas in Changing World", en Proceedings of the Fourth International Conference on Science and Management of Protected Areas. Canadá, SAMPAA.

FLORES, D. y BARROSOS, M. (2012): «El turismo como estrategia de desarrollo rural sostenible. Los parques naturales andaluces». Revista de Estudios Empresariales. Segunda época, $\mathrm{n}^{\circ} 1$, pp. 59-83.

GARCÍA-MORA, R. y MONTES DEL OLMO, C. (2010): El desafío de la gestión de los espacios naturales de Andalucía en el siglo XXI. Documento de Bases. Consejería de Medio Ambiente, Junta de Andalucía.

GÓMEZ-LIMÓN, J. y GARCÍA-VENTURA, D. (2014): Capacidad de acogida de uso público en los espacios naturales protegidos $n^{\circ} 3$. Organismo Autónomo de Parques Nacionales. Madrid. 
GONZÁLEZ-REINA, F. (2012): Evaluación de las actuaciones de la ordenación de accesos en el Parque Regional de Calblanque, Monte de las Cenizas y Peña del Águila. Trabajo Fin de Carrera. Universidad de Murcia.

JORDÁN, E. (2009): Plan Integral de Ordenación de Accesos al Parque Regional de Calblanque, Monte de las Cenizas y Peña del Águila. Región de Murcia, Consejería de Agricultura y Agua, Dirección General de Patrimonio Natural y Biodiversidad, 89 p.

LECO, F., PÉREZ, A. y MATEOS, B. (2013): «Uso público y capacidad de carga perceptual en espacios naturales protegidos», Papeles de Geografía, n ${ }^{\circ}$ 57-58, pp. 127-143

LOCKWOOD, L. y WORBOYS, K. (2006): Managing Protected Areas: A global guide. London: Earthscan

LÓPEZ, D. (2009): «Turismo y Gestión de Espacios Protegidos». En XII Congreso Internacional de Turismo, Universidad y Empresa. Valencia, Tirant Lo Blanch.

MACÍAS-OTÓN, A. (2011): Los indicadores de sostenibilidad en la gestión integral de las playas turísticas. Un estudio aplicado al Parque Regional de Calblanque (Murcia). Gran Tour: Revista de Investigaciones Turísticas $\mathrm{n}^{\mathrm{0}}$ 3, pp. 87-100

MANNING, R.E. (2011): Studies in Outdoor Recreation: Search and Research for Satisfaction. Corvallis, OR: Oregon State University Press.

MARTÍN-LÓPEZ, B. y MONTES, C. (2009): "Un marco conceptual para la gestión de las interacciones naturaleza-sociedad en un mundo cambiante". Cuides, n 3, pp. 229-258.

MARTÍN-PERERA, E. (2016): Gestión de la movilidad de los turistas en espacios naturales. El caso del Parque Nacional de las Cañadas del Teide. Trabajo Final de Grado. Universidad de La Laguna

MURCIANATURAL (2018): «Plano actualizado de Calblanque, Monte de las Cenizas y Peña del Águila» Disponible en http://www.murcianatural.carm.es/web/guest/calblanque-monte-de-las-cenizas-y-pena-del-aguila2

MUÑOZ FLORES, J.C. (2006): Turismo y sostenibilidad en Espacios Naturales Protegidos: La Carta europea del Turismo sostenible en la zona volcánica de la Garrotas y el Plan de Desarrollo Sostenible en Cabo de Gata-Níjar. Tesis doctoral (inédita). Girona: Universitat de Girona.

NATIONAL PARKS SERVICE U.S. Department of the Interior (2017): «Yellowstone National Park». Disponible en https://www.nps.gov/yell/index.htm

NEWSOME, A., MOORE, K., DOWLING (2013): Natural Area Tourism: Ecology, Impacts and Management. 2nd Edition. Toronto: Channel View Publication.

OISMA (2015a): Memoria de gestión del Parque Regional de Calblanque, Monte de las Cenizas y Peña del Águila. Murcia. Comunidad Autónoma de la Región de Murcia.

OISMA (2015b): Programa de Información, Atención al Visitante y Comunicación Social del Parque Regional de Calblanque, Monte de las Cenizas y Peña del Águila. Murcia. Comunidad Autónoma de la Región de Murcia.

OISMA (2016a): Plan de Gestión Integral de los Espacios Protegidos del Mar Menor y la Franja Litoral Mediterránea de la Región de Murcia. Volumen II. Murcia. Consejería de Agua, Agricultura y Medio Ambiente.

OISMA (2016b): Programa de Información, Atención al Visitante y Comunicación Social del Parque Regional de Calblanque, Monte de las Cenizas y Peña del Águila. Murcia. Comunidad Autónoma de la Región de Murcia. 
OISMA (2017): Programa de Información, Atención al Visitante y Comunicación Social del Parque Regional de Calblanque, Monte de las Cenizas y Peña del Águila. Murcia. Comunidad Autónoma de la Región de Murcia.

STRICKLAND-MUNRO, J. y MOORE, S. (2014): «Exploring the impacts of protected area tourism on local communities using a resilience approach», Koedoe 56 (2), Art. \#1161, 10 pages.

UNIÓN EUROPEA (1992): Directiva 92/43/CEE del Consejo, de 21 de mayo de 1992, relativa a la conservación de los hábitats naturales y de la fauna y flora silvestres. Bruselas.

UNIÓN EUROPEA (2009): Directiva 2009/147/CE del Parlamento Europeo y del Consejo, de 30 de noviembre de 2009, relativa a la conservación de las aves silvestres. Bruselas. 